\title{
Investigation of Solvent Effects on NMR Shielding Tensors of Tripeptide Tyr-Aaa-Gly
}

\author{
EBRAHIM BALALI ${ }^{1 *}$ and MASOOME SHEIKHI² \\ 'Department of Chemistry, Pharmaceutical Sciences Branch, Islamic Azad University, Tehran, Iran. \\ ${ }^{2}$ Young Researchers and Elite Club, Gorgan Branch, Islamic Azad University, Gorgan, Iran. \\ ${ }^{*}$ Corresponding author E-mail: e.balali93@gmail.com \\ http://dx.doi.org/10.13005/ojc/300319
}

(Received: May 10, 2014; Accepted: June 18, 2014)

\begin{abstract}
The unique structure of adamantane is reflected in its highly unusual physical and chemical properties, which can have many applications including drug design and drug delivery. Tripeptide Tyr-Aaa-Gly is methionine-enkephalin analogues [Aaa $=(R, S)$-(1-adamantyl)glycine]. In this research, according to Quantum-mechanical calculations nuclear, shielding parameters of Tripeptide Tyr-AaaGly, such as chemical shift isotropic value $\left(\sigma_{\text {iso }}\right)$ and the anisotropy shielding $\left(\sigma_{\text {aniso }}, \Delta \sigma\right)$, and other parameter such as $\delta, \rho$ and atomic charge water have been taken into account using GIAO method at the HF method with the $3-21 \mathrm{G}, 6-31 \mathrm{G}$ and $6-31 \mathrm{G}^{*}$ basis sets and at the B3LYP method with the 3-21G, 6-31G and STO-3G basis sets in the gas phase and in different solvents such as, DMSO, methanol, ethanol and dichloromethane.
\end{abstract}

Key words: Tripeptide Tyr-Aaa-Gly; adamantane; enkephalin; gas phase; solvent effect.

\section{INTRODUCTION}

Diamondoid molecules are cage-like, ultrastable, saturated hydrocarbons. These molecules are ringed compounds, which have a diamond-like structure consisting of a number of six-member carbon rings fused together. More explicitly, they consist of repeating units of ten carbon atoms forming a tetra-cyclic cage system ${ }^{1-3}$. They are called "diamondoid" because their carbon-carbon framework constitutes the fundamental repeating unit in the diamond lattice structure. This structure was first determined in 1913 by Bragg and Bragg $^{4}$ using X-ray diffraction analysis. The first and simplest member of the diamondoids group, adamantane, is a tricyclic saturated hydrocarbon (tricyclo[3.3.1.1]decane). Adamantane nucleus was first built up by Prelog and Seiwerth in 1941 via aluminum chloride-catalyzed isomerization of tetrahydrodicyclopentadiene ${ }^{5}$, this chemical synthesis was latterly improved via catalytic hydrogenation of dicyclopentadiene in the presence 
of aluminum chloride ${ }^{6}$. The unique structure of adamantane is reflected in its highly unusual physical and chemical properties, which can have many applications including drug design and drug delivery. The carbon skeleton of adamantine comprises a cage structure, which may be used for the encapsulation of other compounds, like drugs. Although adamantane has been the subject of many research projects in the field of pharmacophore-based drug design, its application to drug delivery and drug targeting systems is a new matter of considerable importance ${ }^{7}$. Due to the high lipophilicity of adamantane, the incorporation of the adamantyl moiety into several molecules results in compounds with relatively high lipophilicity, which in turn can modify the biological availability of these molecules. After the discovery of amantadine in 1960 as antiviral and antiparkinsonian drug, adamantane derivatives attracted the attention of several scientists as potential chemotherapeutic agents. As a result of this intensive search, thousands of adamantane derivatives were synthesized and tested for several biological activities. This resulted in the discovery of several drugs which are now available in market. Among the major biological activities displayed by adamantane derivatives, the antiviral ${ }^{8}$, antibacterial ${ }^{9}$, antifungal ${ }^{10}$, anti-inflammatory ${ }^{11}$, central nervous ${ }^{12}$ and $11 \mathrm{~b}-\mathrm{HSD} 1$ inhibitory activities ${ }^{13}$ are the most important ones.

Opioid peptides act as cell growth factors, in addition to regulating neurotransmission/ neuromodulation in the nervous system. An enkephalin is a pentapeptide involved in regulating nociception in the body. The enkephalins are termed endogenous ligands, or specifically endorphins, as they are internally derived and bind to the body's opioid receptors. Discovered in 1975, two forms of enkephalin were revealed, one containing leucine ("leu"), and the other containing methionine ("met"). Both are products of the proenkephalin gene. The native opioid growth factor (OGF), methionineenkephalin (Tyr-Gly-Gly-Phe-Met), plays a role in cell proliferation and tissue organization during development, cellular renewal, wound healing, and angiogenesis, but also in cancer ${ }^{14,15}$. To obtain more selective opioid peptides with improved or novel activity profiles toward malignant diseases, modifications using lipophilic moieties may be of particular benefit to passive or active cellular absorption by membrane penetration or attachment. The susceptibility of the modified peptides to enzymatic degradation may also decrease. The enkephalins are considered to be the primary endogenous ligands of the ä-opioid receptor, due to their high potency and selectivity for the site over the other endogenous opioids.

\section{Methods of Computations}

At first, we have modeled the Tripeptide TyrAaa-Gly (Figure 1) with ChemDraw package. Then using Chem3D performed an energy minimization. The ab initio molecular calculations were carried out using the Gaussian 98 program. Gaussian is one of the most widely used quantum chemical program packages for molecular applications, and is used both in industry and in many scientific areas in academia. we have calculated the geometric parameters of the compounds in the ground state the using the Hartree-Fock (HF) ${ }^{16}$, Becke's threeparameter hybrid method $^{17}$ and $3-21 \mathrm{G}, 6-31 \mathrm{G}$, 6-31 $\mathrm{G}^{*}$ and STO-3G basis set. If you want to optimize geometry, it means that you want Gaussian to adjust the bond lengths, angles and dihedrals to find the lowest energy conformation of the molecule. First principles means that the integrals are done either using closed formulas or by doing the integrals numerically. The particular $a b$ initio method that works best for calculating NMR properties ${ }^{18,19}$.

The important information is the HartreeFock energy $(\Delta \mathrm{E})$, the Mulliken charges, Distance matrix (angstroms), Dipole moment (Debye) and Atomic charge.

We used Gaussian98 at the NMR calculations using the HF, B3LYP and 3-21G, 6-31G, $6-31 G^{*}$ and Sto-3G basis set ${ }^{20}$. The calculations also provide valuable information for exploring the experimental NMR chemical shifts with the molecular geometry and environment. Also NMR chemical shifts are quite sensitive to intermolecular interactions. NMR is based on the quantum mechanical property of nuclei. The chemical shielding refers to the phenomenon which associated with the secondary magnetic field created by the induced motions of the electrons that surrounding the nuclei when in the presence of an applied magnetic field for chemical shielding (CS) tensors, which describes how the size of shielding varies with molecular orientation, we often use the following convention for the three principle component: 


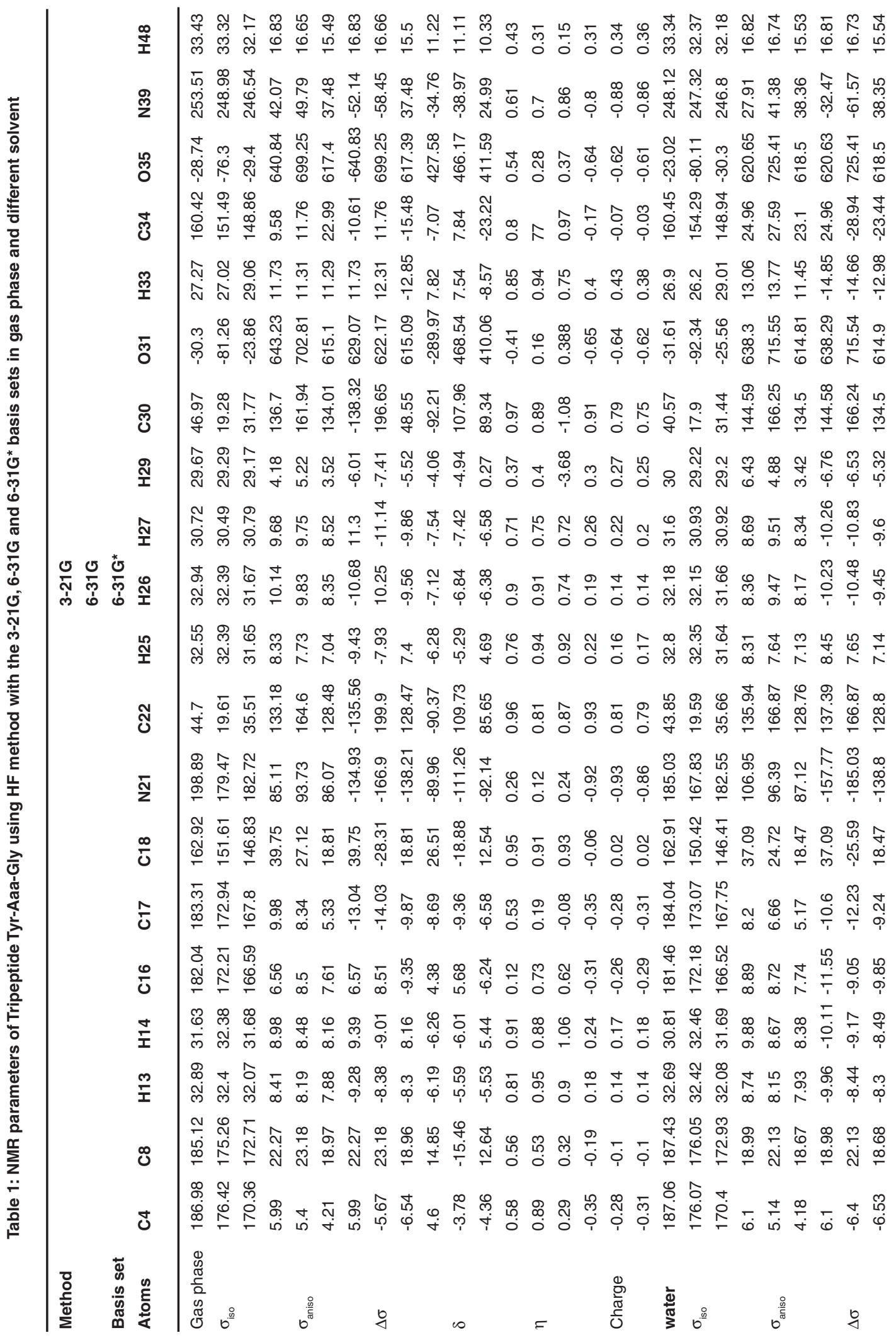


$\bar{\uparrow}$ F 苗员 तิ ผ 等等

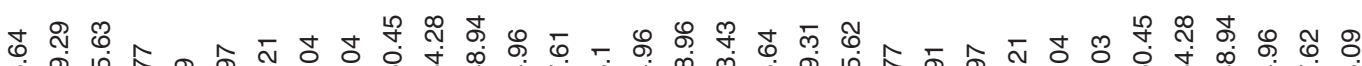
过 它

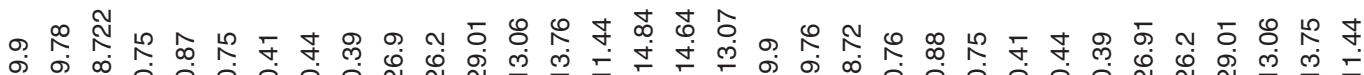
申 กู 岁守过等 ర్ల 岁웅 官

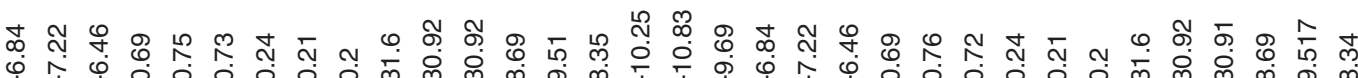
œ

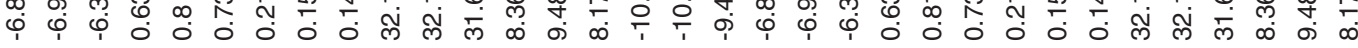
芯

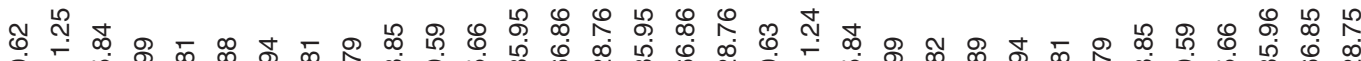

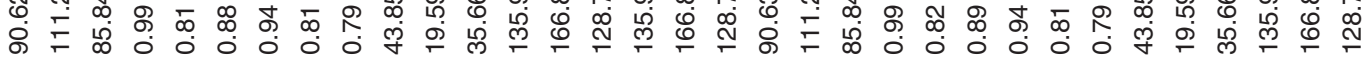

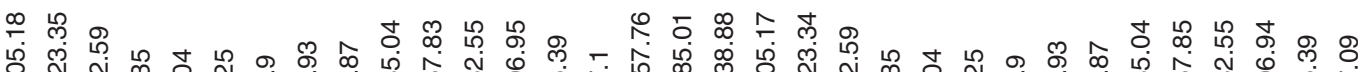

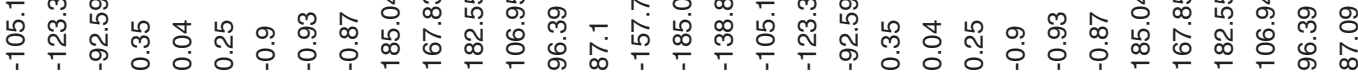
న

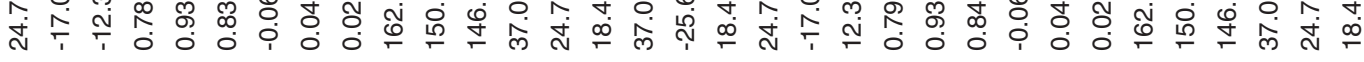

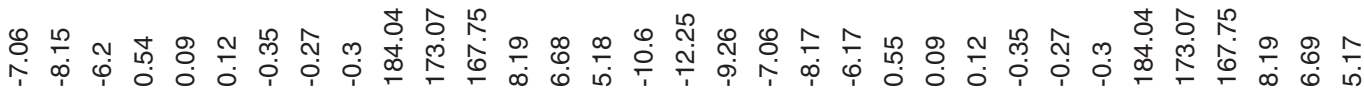

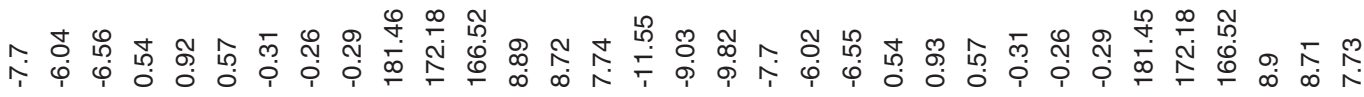

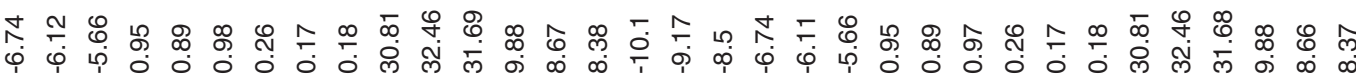

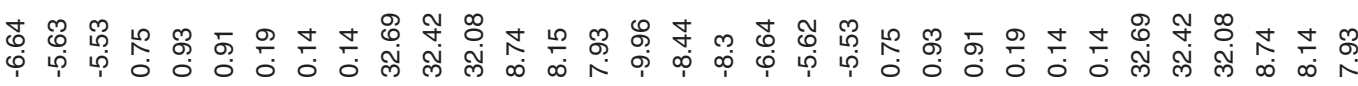

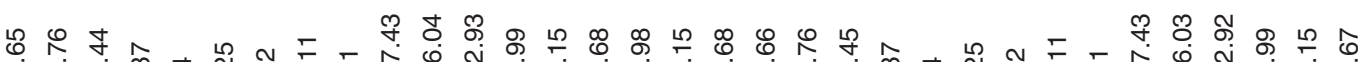

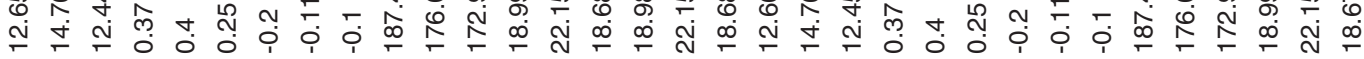

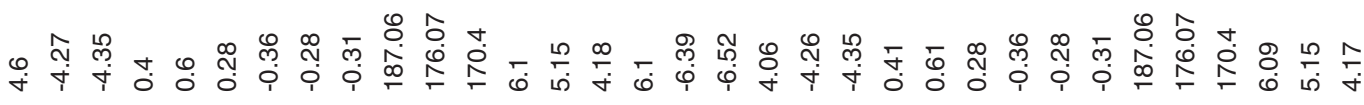

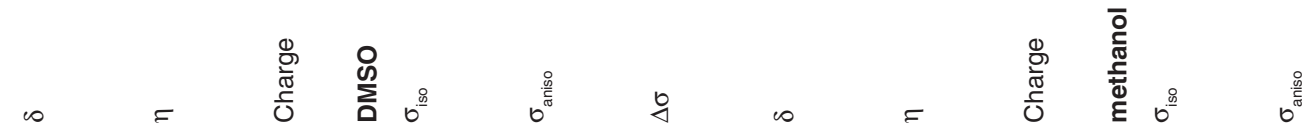




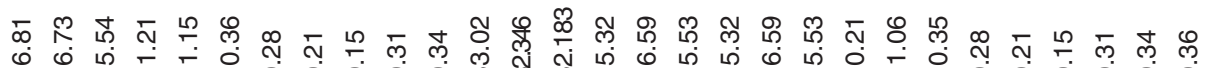

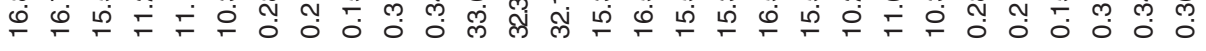

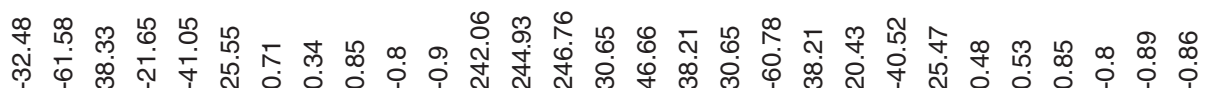

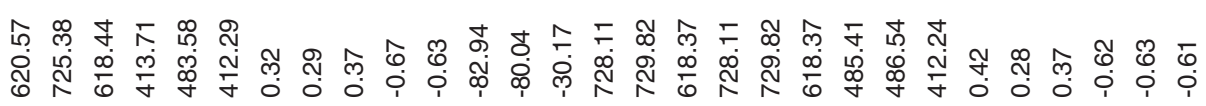

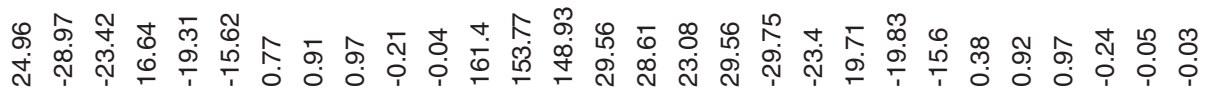
菏

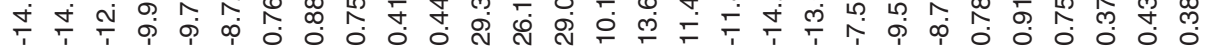

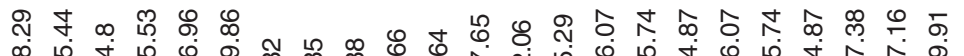

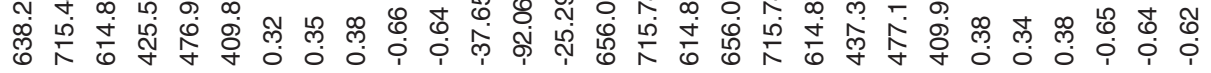

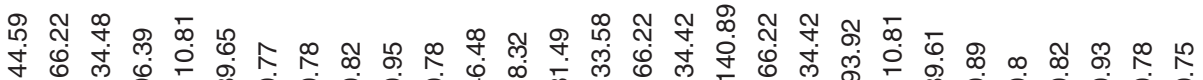

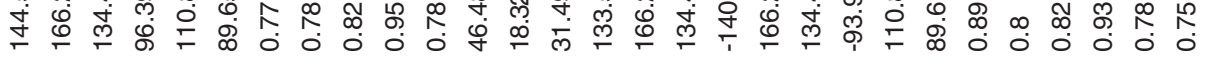

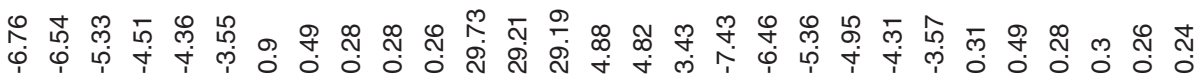

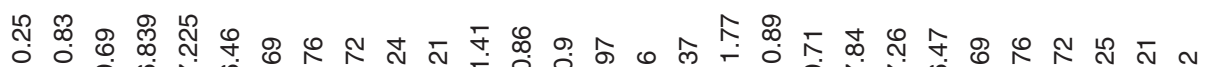
눈 운

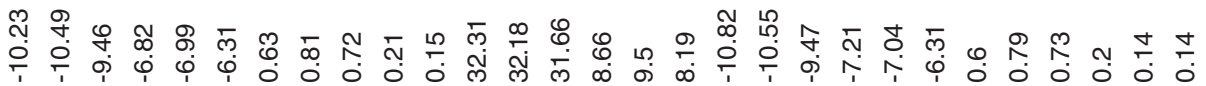

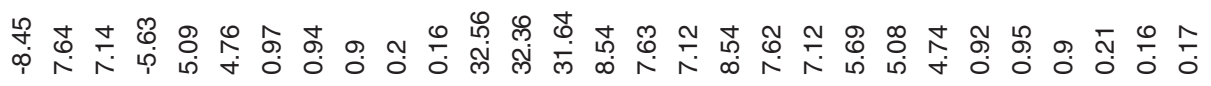

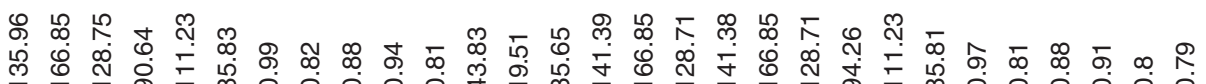

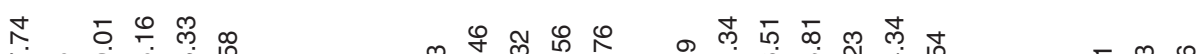
它吊

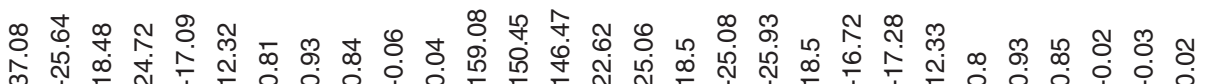

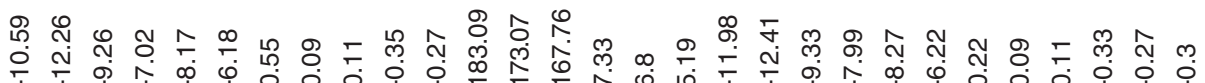
员 ๙

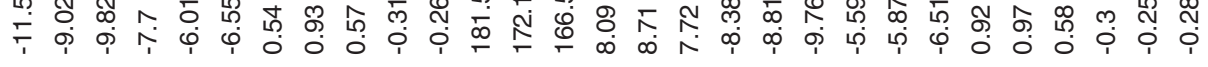

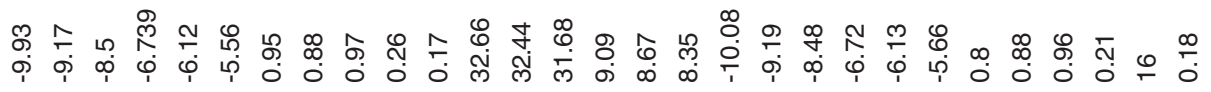

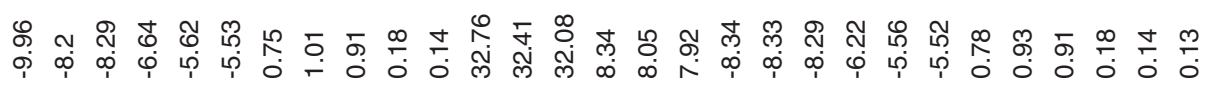

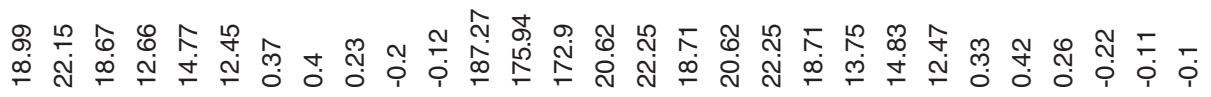

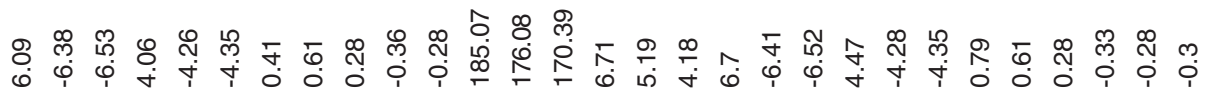

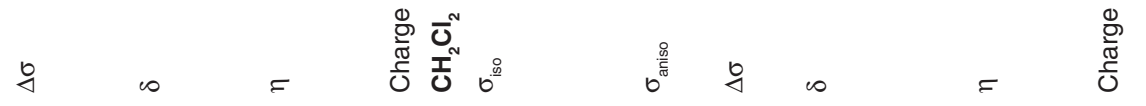




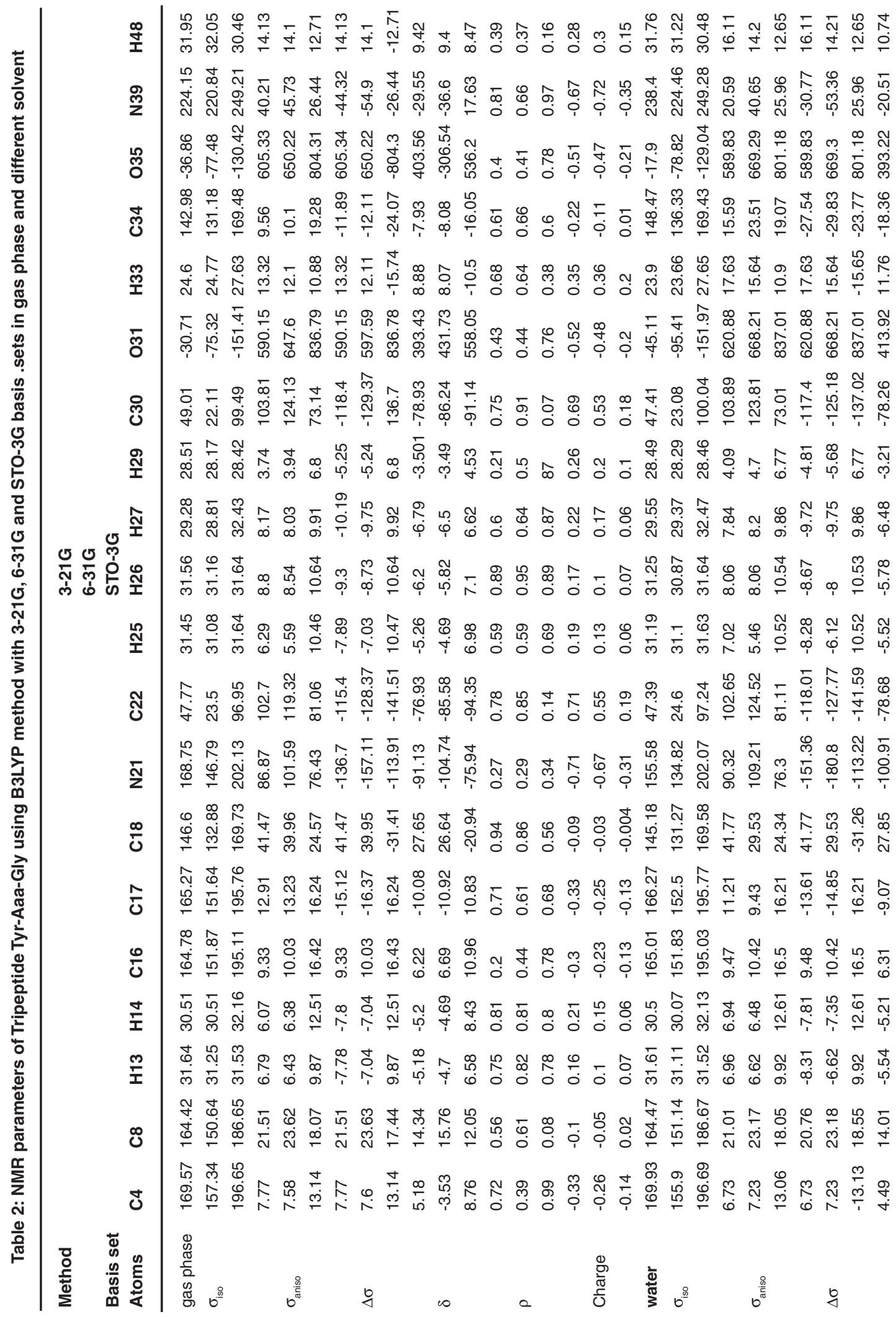




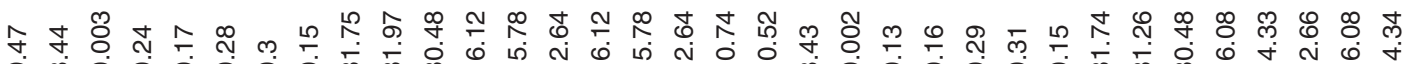
హ

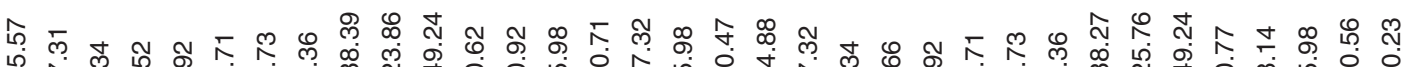

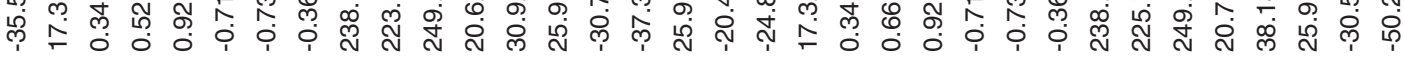

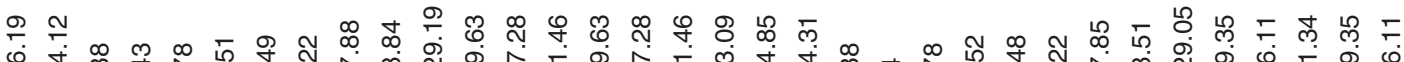

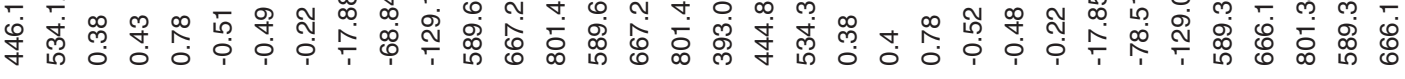
œ

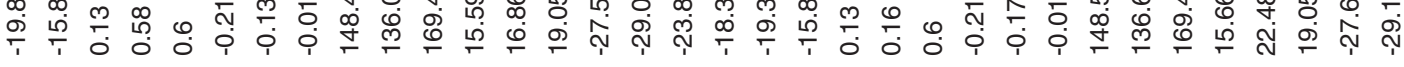
雨

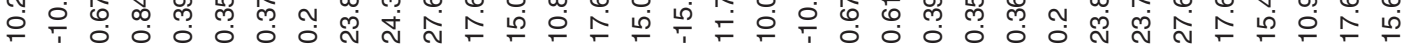

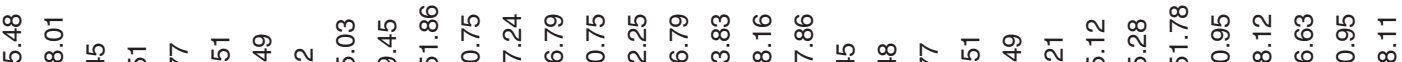

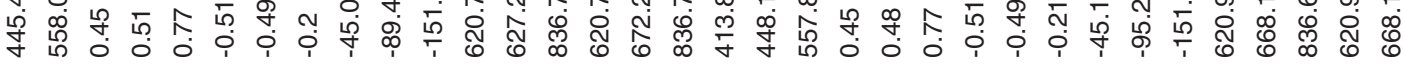
䓇节

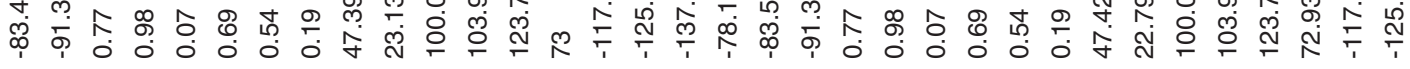

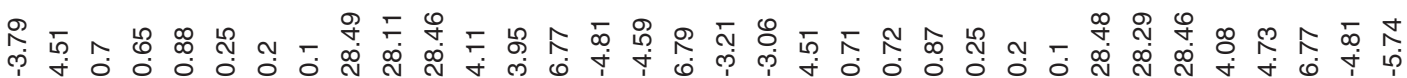
员

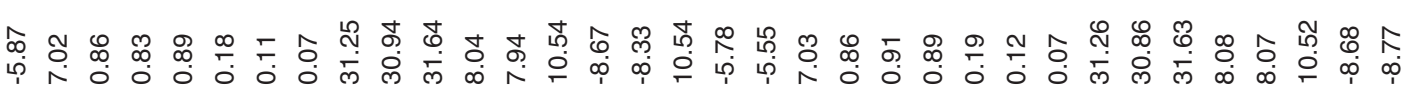
吕 車

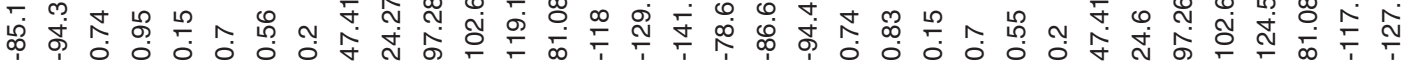

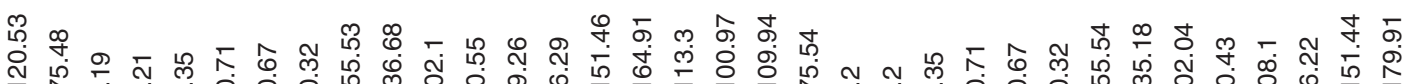
ஃ 苒

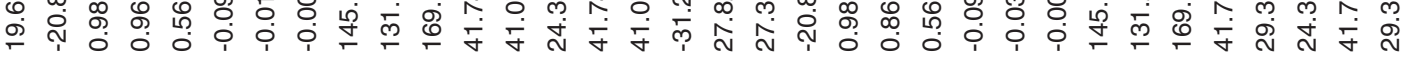
の

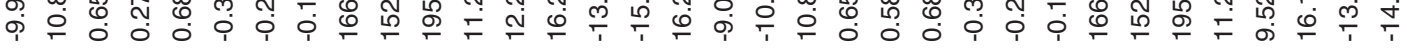

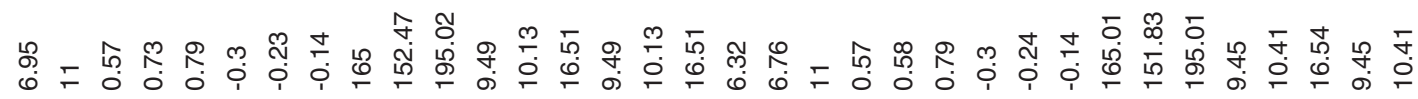

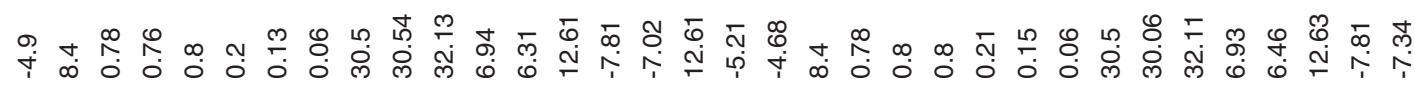

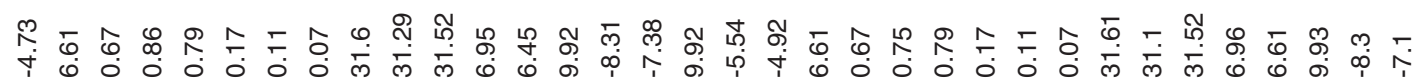

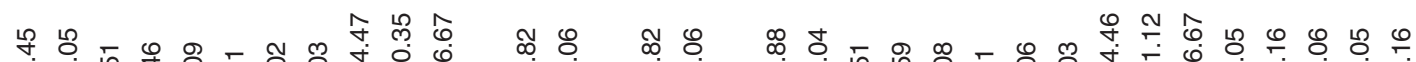

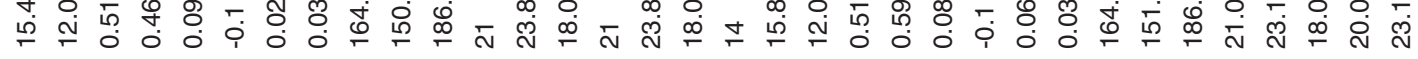

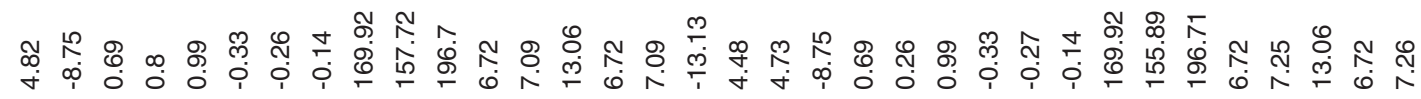

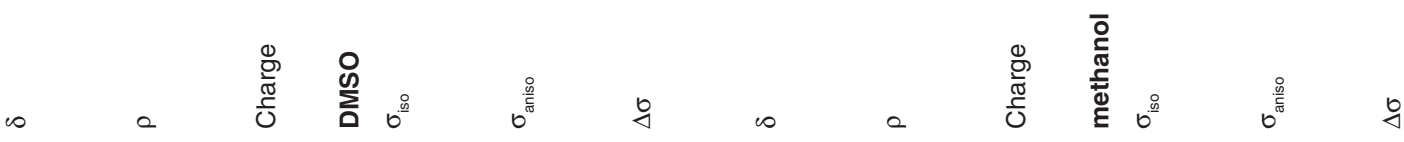


遈

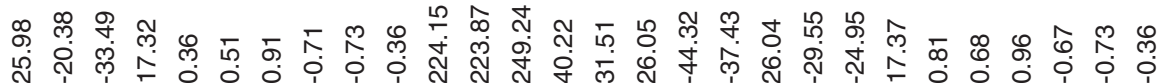
䒠 $0 \hat{0}$ N

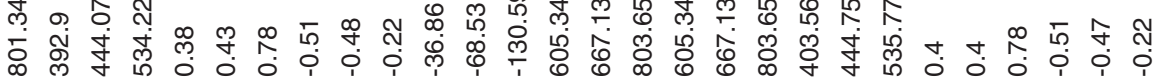
๖ ₹ ᄂ đֶ๊

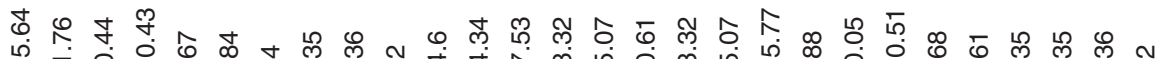

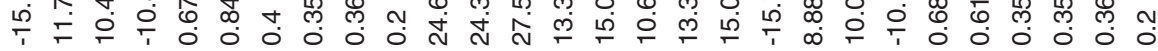

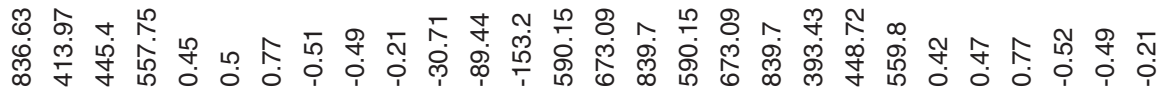

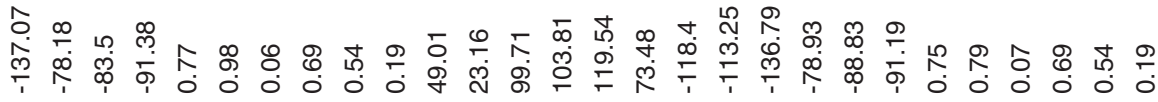

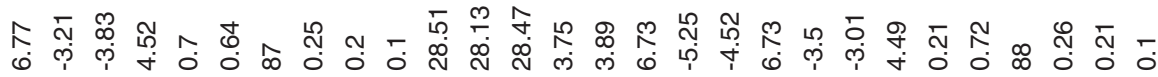

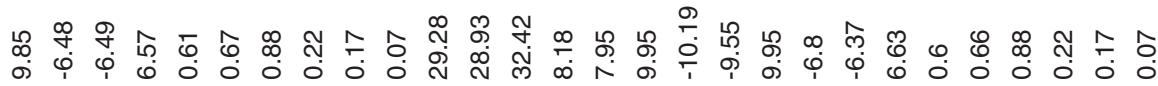

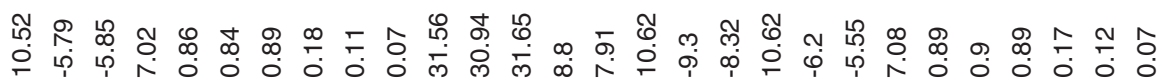

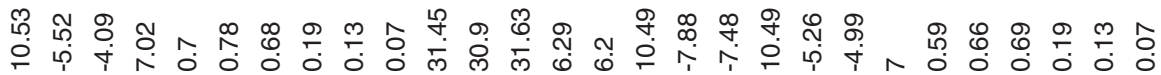

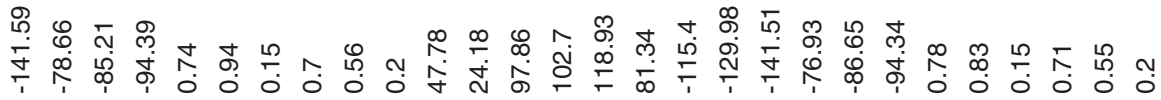

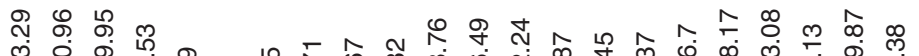
m T T

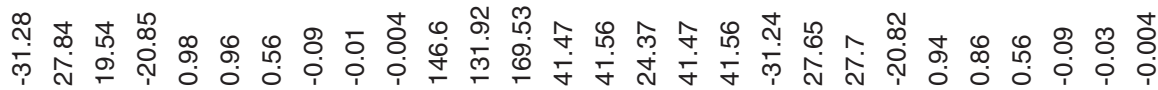

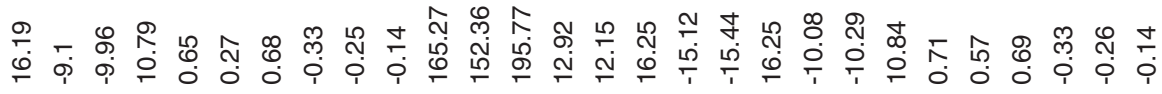

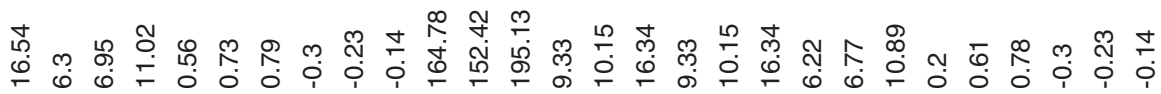

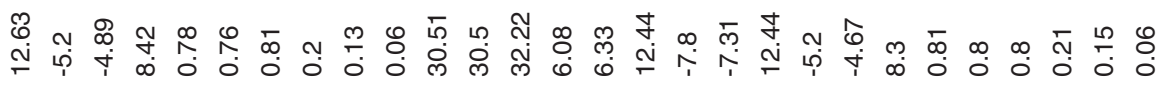

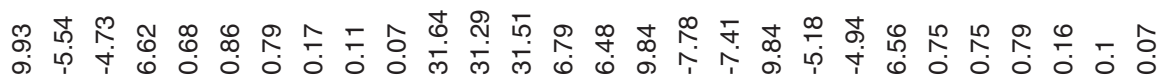

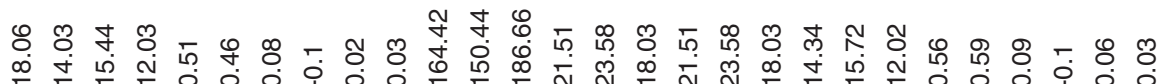

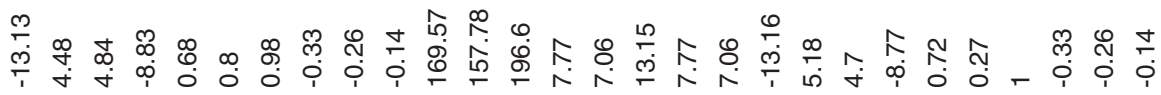

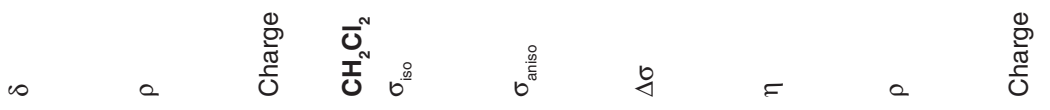



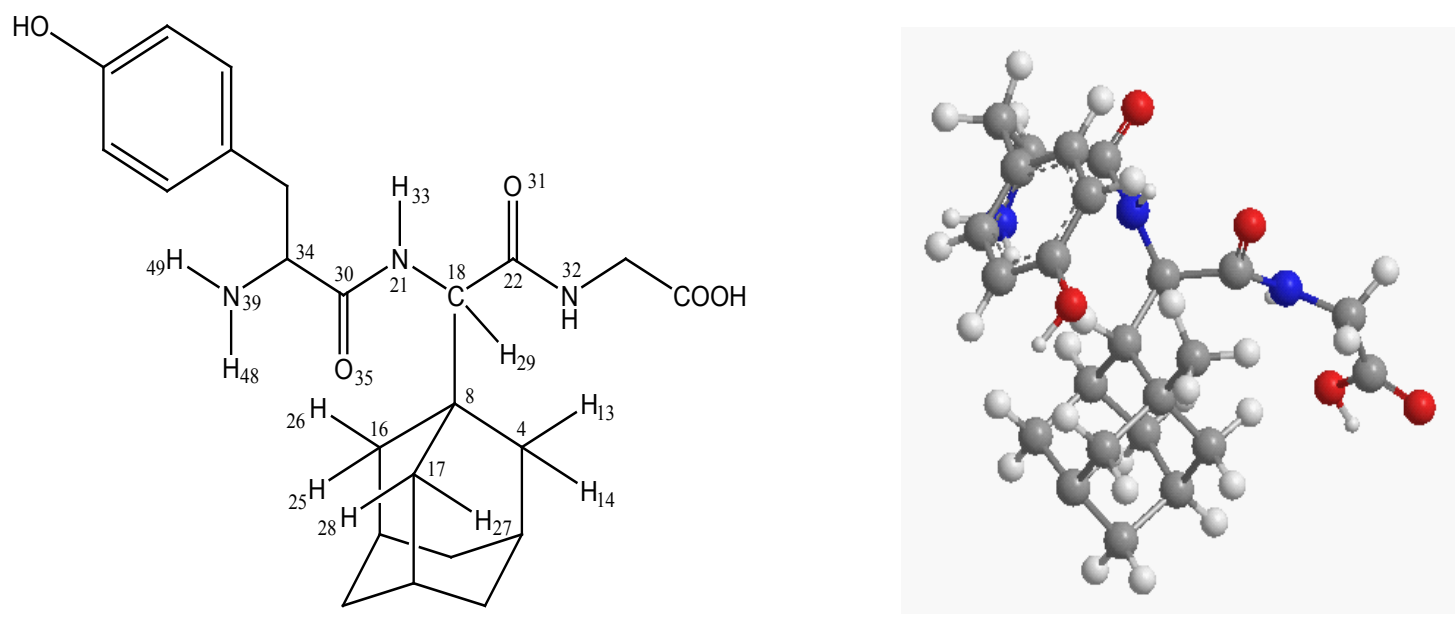

Fig. 1: Structure of Tripeptide Tyr-Aaa-Gly

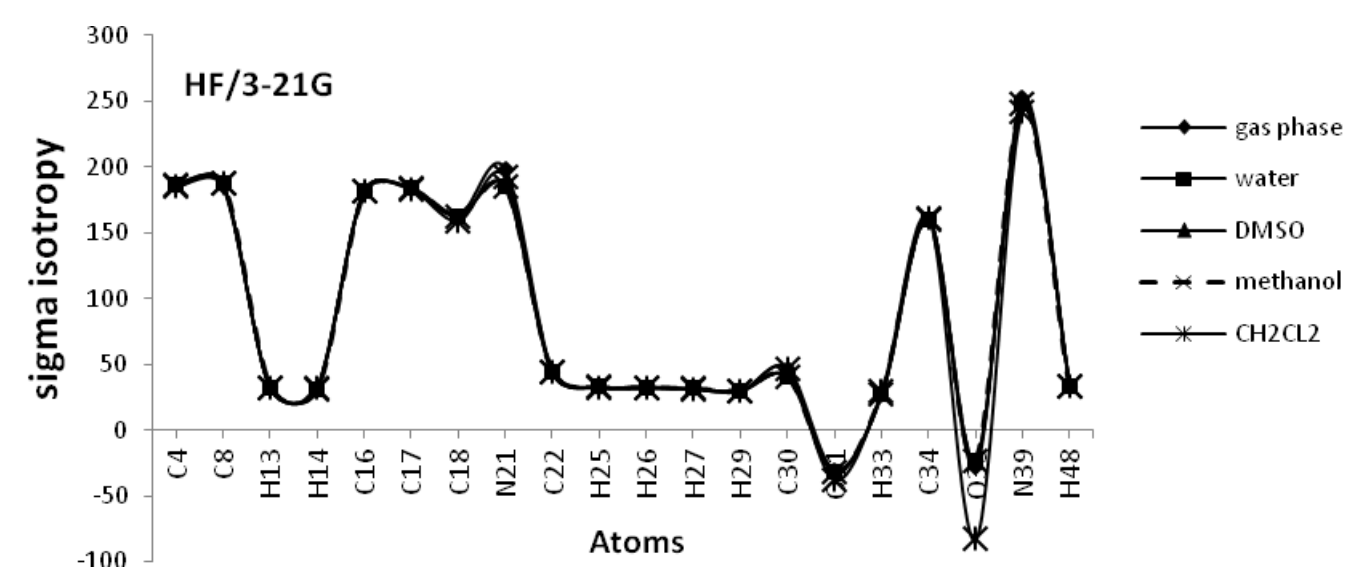

Fig. 2: The graph of isotropic shielding values $\left(\sigma_{\text {iso }}\right)$ of atoms of Tripeptide

Tyr-Aaa-Gly in gas phase and four solvents at the HF/3-21G level

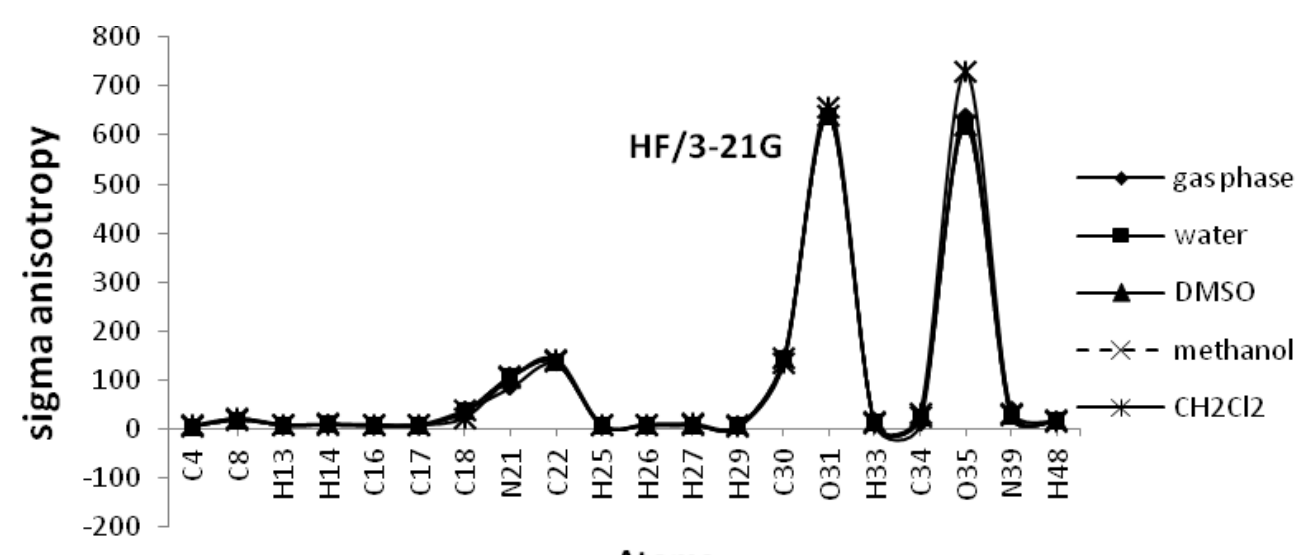

Atoms

Fig. 3: The graph of anisotropic shielding values $\left(\sigma_{\text {aniso }}\right)$ of atoms of Tripeptide Tyr-Aaa-Gly in gas phase and four solvents at the HF/3-21G level 


$$
\sigma_{11} \leq \sigma_{22} \leq \sigma_{33}
$$

The three values of the shielding tensor are frequently expressed as the isotropic value $\left(\sigma_{\text {iso }}\right)$, the anisotropy shielding $\left(\sigma_{\text {aniso }}\right)$ and the other parameters such as $\delta, \eta$ and $\Delta \sigma$. In our current study, extensive quantum mechanical calculation of Tripeptide TyrAaa-Gly and solvent effects on NMR parameters of selective atoms have been performed in different solvent media and gas phase in six methods using Gaussian 98 program²1,22.

In this section we report and analyze the solvent effects on our NMR shielding tensors of selective atoms of Tripeptide Tyr-Aaa-Gly (Figure 1) obtain at the HF method with the 3-21G, 6-31G and $6-31 G^{*}$ basis sets and at the B3LYP method with 3-21G, 6-31G and STO-3G basis set. In our current research, we have presented the results of our extensive studies of solvent induced effects on the $\mathrm{C}, \mathrm{N}$ and $\mathrm{H}-\mathrm{NMR}$ shielding of molecule in a wide range of solvents encompassing a broad spectrum of polarity and hydrogen-bonding properties. According to our theoretical data, it is apparent that the solvent effects seem quite significant in physicochemical behavior. At first the shielding variation seems to follow the polarity of solvent in the sense of enhanced deshielding with the increasing polarity. The $\mathrm{C}, \mathrm{N}$, $\mathrm{O}$ and $\mathrm{H}-\mathrm{NMR}$ parameters of molecule and atomic charges of atoms in various solvent media are given in Table 1 and 2. Two graphs of NMR parameters have been displayed in Figure 2 and 3 using HF/3$21 \mathrm{G}$ level.

Our obtained results yielded strong evidence that intermolecular interactions play very important role in determining the $\mathrm{C}, \mathrm{N}, \mathrm{O}$ and $\mathrm{H}-\mathrm{NMR}$ chemical shielding tensors of our molecule. As shown in Table 1 and 2, the greatest value of chemical shift isotropic $\left(\sigma_{\text {iso }}\right)$ is for $N_{39}$ in water with B3LYP/STO-3G level, also the smallest value of chemical shift isotropic $\left(\sigma_{\text {iso }}\right)$ is observed for $\mathrm{O}_{31}$ in $\mathrm{CH}_{2} \mathrm{Cl}_{2}$ with B3LYP/STO-3G level. Of carbon atoms in the Table 1 and $2 \mathrm{C}_{4}$ has greatest value of chemical shift isotropic in methanol with B3LYP/ STO-3G, also of hydrogen atoms in the Table 1 and 2, $\mathrm{H}_{48}$ has greatest value of chemical shift isotropic in gas phase with HF/3-21G level. According to Table 1 and 2, the greatest value of chemical shift anisotropy $\left(\sigma_{\text {aniso }}\right.$ ) observed for $\mathrm{O}_{31}$ in $\mathrm{CH}_{2} \mathrm{Cl}_{2}$ solvent with B3LYP/ STO-3G level and smallest value of chemical shift isotropic $\left(\sigma_{\text {iso }}\right)$ observed for $\mathrm{H}_{29}$ in water, DMSO and methanol with HF/6-31G* level. As pointed in Table 1 and 2 the largest positive value of ä was observed for $\mathrm{O}_{31}$ in $\mathrm{CH}_{2} \mathrm{Cl}_{2}$ with B3LYP/Sto-3G level, while the largest negative value belongs to $\mathrm{N}_{21}$ in $\mathrm{CH}_{2} \mathrm{Cl}_{2}$ with HF/6-31G level. According to Table 1 and 2, the largest value of ç was observed for $\mathrm{H}_{13}$ in methanol with HF/6-31G level, while the smallest value for $\mathrm{H}_{29}$ in gas phase with $\mathrm{HF} / 6-31 \mathrm{G}^{*}$ level. As shown in Table 1 and 2, $\mathrm{O}_{35}$ has the greatest value of Äó in $\mathrm{CH}_{2} \mathrm{Cl}_{2}$ with B3LYP/STO-3G level, while $\mathrm{O}_{35}$ has the smallest value in gas phase with B3LYP/STO-3G level. As pointed in Table 1 and 2, the largest positive value of atomic charge was observed for $\mathrm{C}_{22}$ in water, DMSO and methanol with HF/3-21G level, while the largest negative value belongs to $\mathrm{N}_{21}$ in gas phase and four solvent with HF/6-31G level.

\section{CONCLUSION}

In our current research, we have theoretically studied the effects of water, DMSO, methanol, dichloromethane and gas phase on NMR Shielding Tensors of Tripeptide Tyr-Aaa-Gly involving in active site. The parameters calculated using six levels. The smallest value of chemical shift isotropic $\left(\sigma_{\text {iso }}\right)$ and the greatest value of chemical shift anisotropy $\left(\sigma_{\text {aniso }}\right)$ observed for $\mathrm{O}_{31}$ in $\mathrm{CH}_{2} \mathrm{Cl}_{2}$ solvent with B3LYP/STO$3 \mathrm{G}$ level. Therefore $\mathrm{O}_{31}$ greater extent is influenced by magnetic field.

\section{REFERENCES}

1. Fort, R. C. Adamantane, The chemistry of diamond molecules (Studies in organic Chem.; v. 5), Marcel Dekker, New York, (1976).

2. Olah, G. A. Cage Hydrocarbons. J. Wiley \& Sons, New York, NY, (1990).

3. Marchand, A. P. Science. 2003, 299, 52-53.
4. Bragg, W. H.; Bragg, W. L. Nature, 1913, 91 , 554-556.

5. Prelog, V.; Seiwerth, R. Ber. 1941, 74B, 16441648.

6. Prelog, V.; Seiwerth, R. Ber. 1941, 74B, 1769- 
1772.

7. Ramezani, H.; Mansoori, G. A. Diamondoids as Molecular Building Block for Nanotechnology, Drug Targeting and Gene delivery, to appear (2006).

8. Wendel, H. A.; Snyder, M. T.; Pell, S. Clin. Pharmacol. Therap. 1966, 7, 38-43.

9. Krimmel, C. P. U.S. Patent. 1971, 3, 565,942.

10. Georgiev, V. S.; Bennett, G. A.; Radov, L. A.; Kamp, D. K.; Trusso, L. A. Arch. Pharm. 1987, 320, 465-470.

11. Krimmel, C. P. U.S. Patent. 1968, 3, 374,244.

12. Schwab, R. S.; England, A. C.; Poskanzer, D. C.; Young, R. R. J. Am. Med. Assoc. 1969, 208, 1168-1170.

13. Balkovec, J. M.; Thieringer, R.; Mundt, S. S.; Hermanowski-Vosatka, A.; Graham, D. W.; Donald, W.; Patel, G. F.; Susan, S. D.; Waddell, S. T.; Sherman, T.; Olson, S. H.; Maletic, M. PCT Int. Appl. WO 20030814; Chem. Abstr. 2003, 139, 180065.

14. Zagon, I. S.; Verderame, M. F.; McLaughlin, P. J. Brain Res. Rev. 2002, 38, 351-376.

15. Smith, J. P.; Conter, R. L.; Bingaman, S. I.;
Harvey, H. A.; Mauger, D. T.; Ahmad, M.; Demers, L. M.; Stanley, W. B.; McLaughlin, P. J.; Zagon, I. S. Anti-Cancer Drugs. 2004, 15, 203-209.

16. Moller, C.; Plesset, M. S. Phys. Rev. 1934, 46, 618-622.

17. Becke, A. D. Phys. Rev. A. 1988, 38, 30983100.

18. Monajjemi, M.; Honaparvar, B.; Khalili Hadad, B.; Ilkhani, A. R.; Mollaamin, F. Afr. J. Pharm. and Pharmacol. 2010, 4, 521-529.

19. Monajjemi, M.; Afsharnezhad, S.; Jaafari, M. R.; Abdolahi, T.; Nikosade, A.; Monajemi, $\mathrm{H}$. Russ. J. Phys. Chem. A. 2007, 81, 1956-1963.

20. Monajjemi, M.; Azad, M. T.; Haeri, H. H.; Zare, K.; Hmedani, S. J. Chem. Res. 2003, 8, 454456.

21. Mollaamin, F.; Shahanipoor, K. Nejadsattari, T.; Monajjemi, M. Afric. J. Micro. Res. 2010, 4, 2098-2108.

22. Monajjemi, M.; Heshmat, H.; Haeri, H. H.; Keveh, F. Russ. J. Phys. Chem. 2006, 80, 1061-1068. 